\title{
DESIGN AND DEVELOP CERTIFICATE VALIDATION SYSTEM USING SMART CONTRACT
}

\author{
Ashwini Bacholkar, Vaibhavi Shinde, Komal Sonawane, Rohit Jagtap \\ BE Student, Dept. of Computer Engineering, \\ Trinity Academy of Engineering, Pune, India \\ Prof. Santosh Darade \\ Assistant Professor, Dept. of Computer Engineering \\ Trinity Academy of Engineering, Pune, India
}

\begin{abstract}
As per us information, near about one million student pass out from college each year, after completion Degree or Graduation some of student will be ready to enter the workplace employment. During all education, the students get performance certificates and marksheet year wise, etc., this document will become an important for admission of new colleges or new works. As schools make various awards or diplomas, only the names of the schools and the students are input. Due to the insufficiency anti-forge cases, events that cause the graduation certificate to be fake often get observe. In order to solve the Problem using digital certificates, the digital certificate system based on blockchain technology would be proposed. Due to the original attribute of blockchain, the online certificate with anti-counterfeit and verifiability could be made. The procedure of issuing the digital certificate in this system is included. First, generate the E-certificate and certificate serial number using hash function also after generate $Q R$ code.
\end{abstract}

Keywords - Blockchain, Digital certificate, Hyperledger, Hashing

\section{INTRODUCTION}

Data Mining is the discovering patterns in large data sets. Include technique at the intersection of expert system, statistics, and database systems. Data mining is associative subset of computer-aided learning with an generally aim to extract data (with quick technique) from a data file and convert the information into a understandable formation for further use. Data mining is the assessment step of the "understanding database" process. Apart from the raw examination step, it also require data-collection and data management angle, data pre-processing replica and connection considerations, snooping metrics, difficulty thought, post-processing of find structure, visualization, and online updating. The term "data mining" is in truth a contradiction, because the aim is the extraction of structure and knowledge from huge quantity data, not the extraction of data its own. It also is a catchword and is regularly applied to any form of huge quantity of data or information dealing with also any application of computer decision

support system, as well as expert system and business intelligence. The book Data mining: actual machine learning tools and tactic with Java was initially to be named just applied machine learning, and the phrase data mining was only attach for peddle cause. frequently the more general condition data inspection and analyze or, when mention to genuine procedure, expert system and machine learning are more suitable. Advances in information technology, the wide availability of the Internet, and common usage of mobile devices have changed the lifestyle of human beings. Digital currency, digital coins originally plan for use online, has begin to be highly affect in real life. Because of the good of the Internet, different digital currencies are booming, including the most amateur-Bit coin, Ether, and Ripple the principle of which has flow lately. community are outset to pay consciousness to blockchain, the foundation hi tech of these total. Block chain features a decentralized and incorruptible database that has high potential for a diverse range of uses. Block chain is a distributed database that is widely used for recording distinct transactions. Once a consensus is reached among different nodes, the transaction is added to a block that already holds records of several transactions. every block contains the hash value of its last part for connection. All the blocks are connected to every one they form a blockchain. Number of Data are distributed among various nodes and are thus scattered. As a result, the every nodes maintain the database jointly. Underneath blockchain, a block became verify only once it has been certified by multiple group. inter, the data in blocks can't be alter aimlessly.

\section{SYSTEM ARCHITECTURE}

System architecture would be to show the relationship between different components. systems which include hardware and software and these component are represented in the diagram to show the interaction between them. System is based on generation of Ecertificate + certificate serial number and QR code for 
students to digitize the document verification system which will reduce the working time and increase the digitization in educational field.

This system architecture totally depends on 3 main character, college, student, company. when student take admission that time he apply for E-certificate. after successfully registration he login and submitted all document like marksheet to the college. After submitting document every student get unique E-certificate + Ecertificate serial number plus QR code. this QR code are printed on student resume so when student are apply for any company that time he only carry resume. no need to carry any marksheets and other document. only submit resume in company. after that company are send to request to college for student verification. once college are verified student are valid or invalid. if student are valid college reply to the company yes, student is valid then company scan the document QR code through.

Figure 1: Block Diagram of proposed system

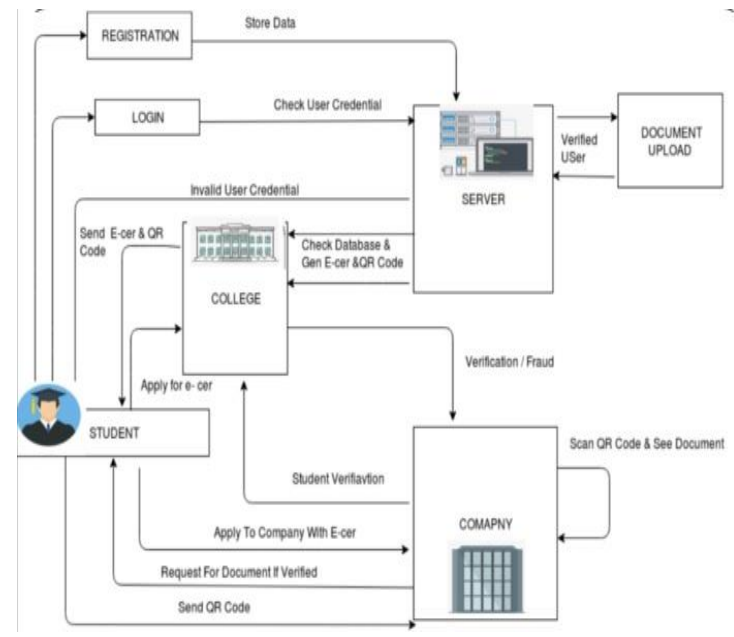

III. SYSTEM IMPLEMENTATION

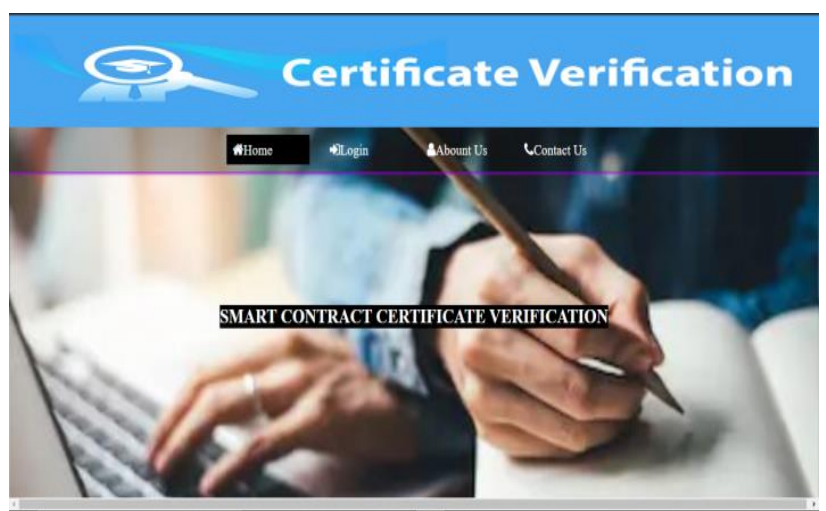

Figure2: Home page

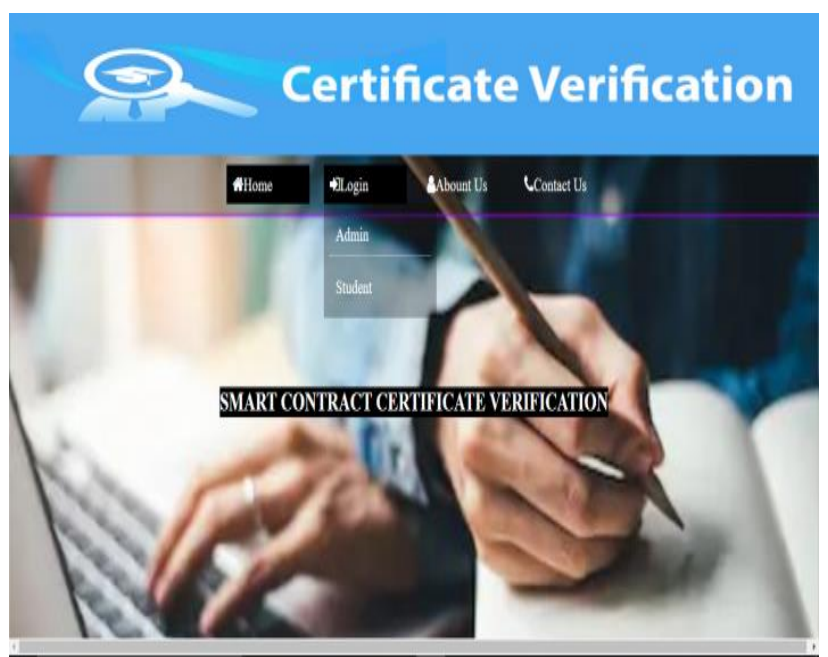

Figure 3: Login modules

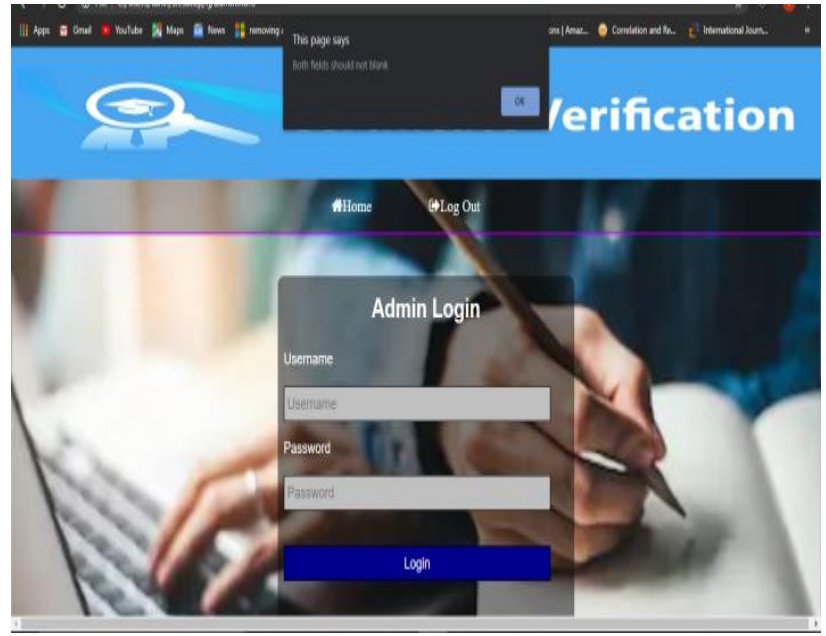

Figure 4: Empty field validation

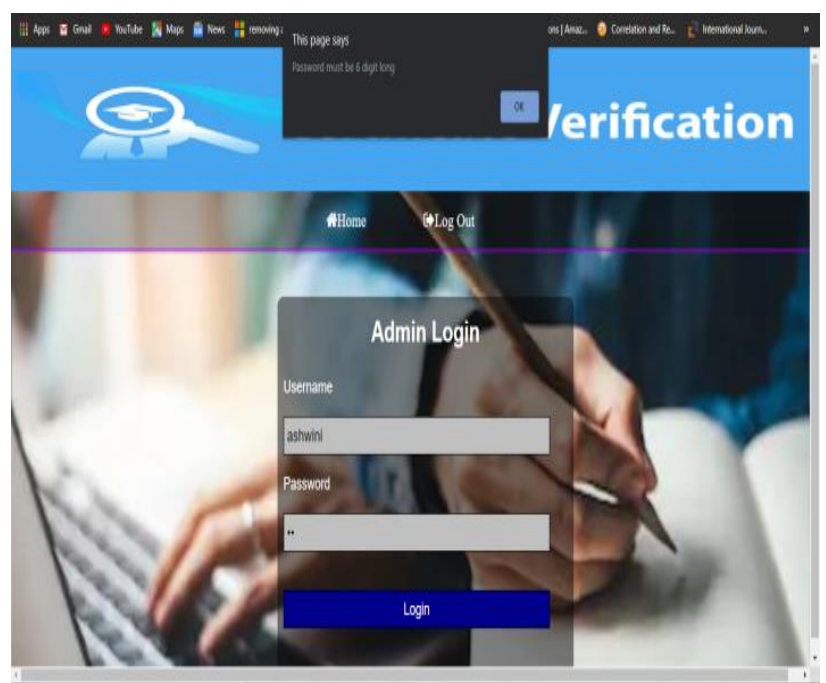

Figure 5: Password field validation 
International Journal of Engineering Applied Sciences and Technology, 2020

Vol. 5, Issue 2, ISSN No. 2455-2143, Pages 549-553

Published Online June 2020 in IJEAST (http://www.ijeast.com)

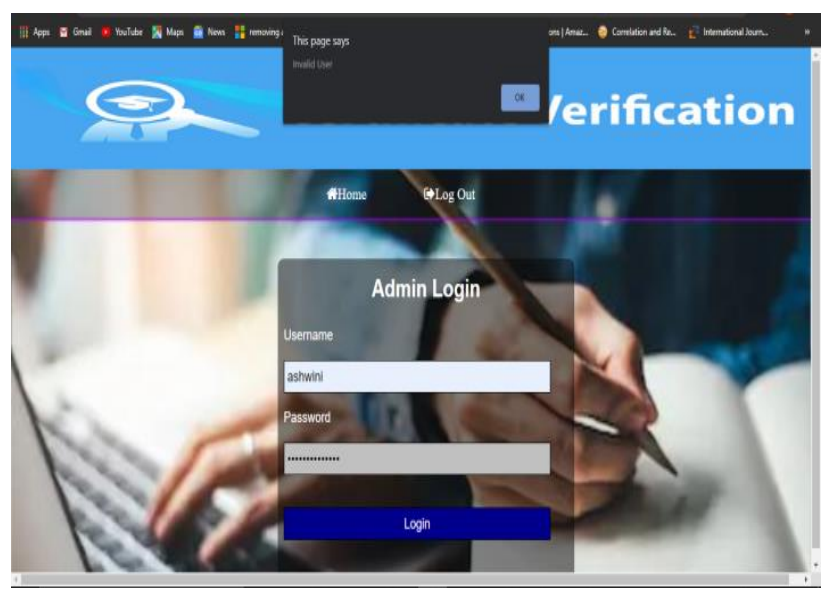

Figure 6 : Invalid user validation

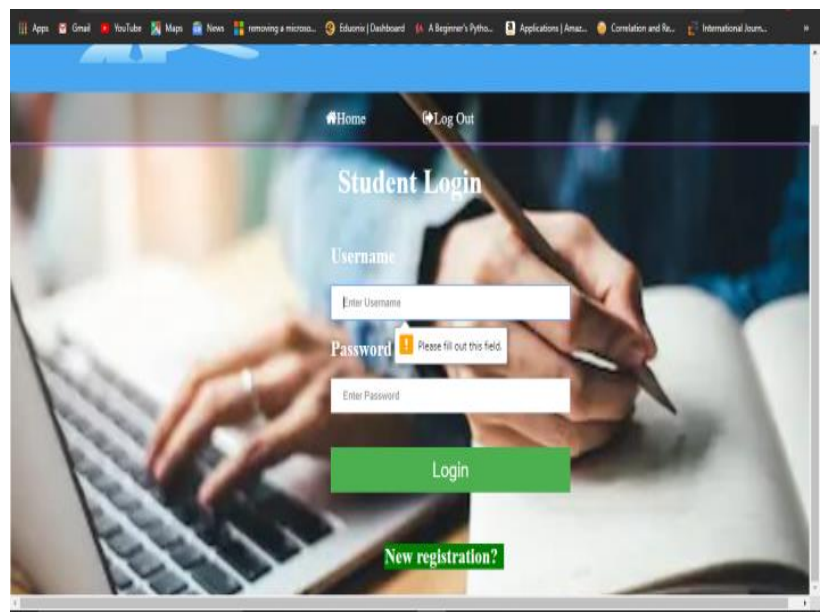

Figure 7: Login

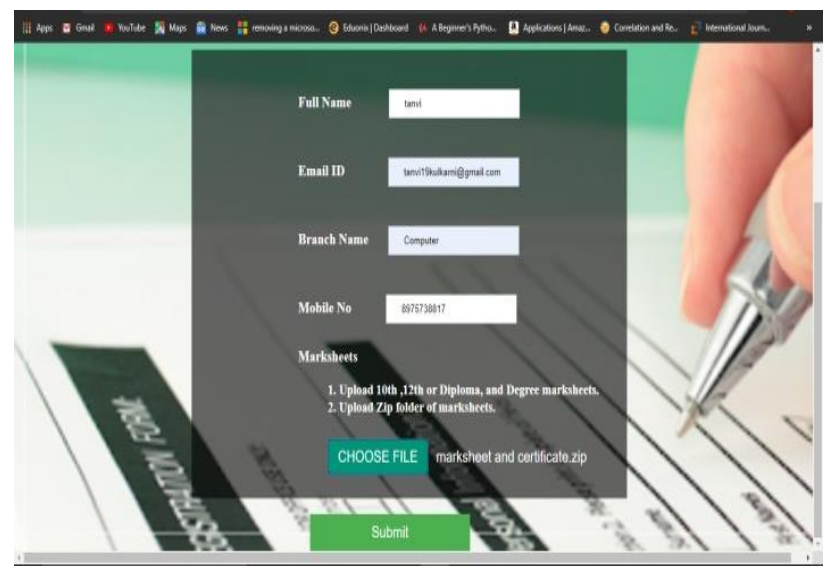

Figure 8 : Registeration

\begin{tabular}{|c|l|l|l|c|c|}
\hline Id & Name & Branch & 10th \% & 12 or diploma \% & BE aggregate \\
\hline 1 & Rohit Jagtap & Computer & 70 & 65 & 50 \\
\hline 2 & Ashwini Bacholkar & Computer & 80 & 82 & 55 \\
\hline 3 & Komal Sonawane & Computer & 79 & 78 & 50 \\
\hline 4 & Valbhavi Shinde & Computer & 85 & 80 & 60 \\
\hline 5 & Tanvi Kulkami & Computer & 60 & 40 & 45 \\
\hline
\end{tabular}

Figure 9: Student data

10 th $\%, 12$ or diploma $\%$ and BE aggregate

- 100\% $\%$ 120rdicioma\% BE aggregate

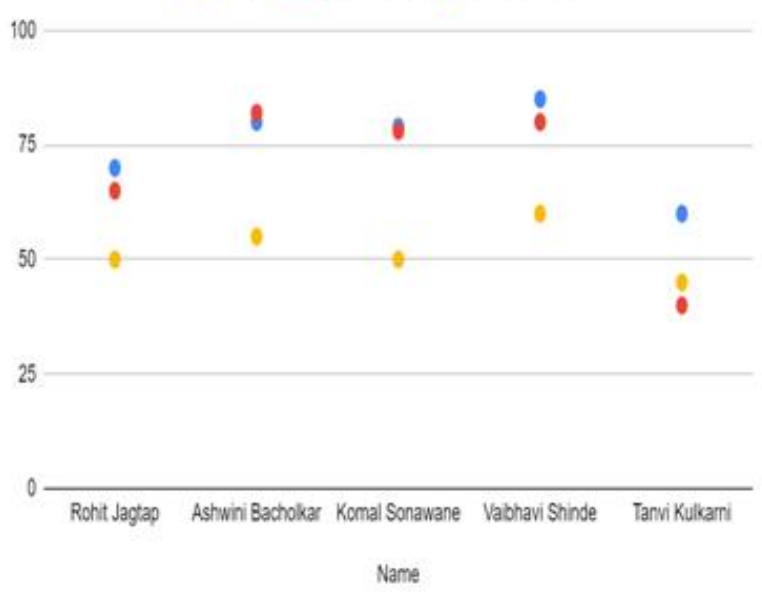

Figure 10: Representation 


\begin{tabular}{|c|c|}
\hline QRCode & Student Name \\
\hline & \\
\hline & Rohit Jagtap \\
\hline & Ashwini Bacholkar \\
\hline & \\
\hline & Komal Sonawane \\
\hline & \\
\hline
\end{tabular}

Figure 11: Result

$=10$ th $\%=12$ or diploma $\%=$ - BE aggregate

100

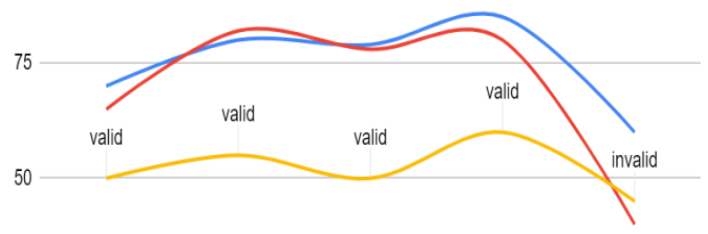

25

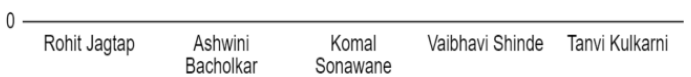

Figure 12: Validation using line chart

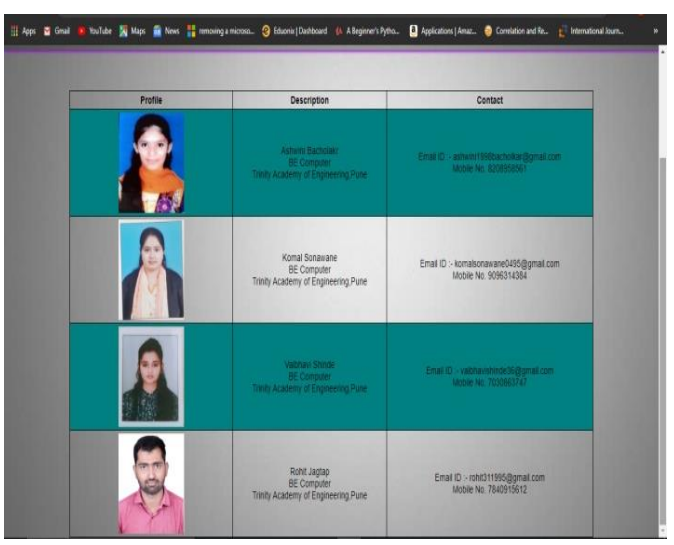

Figure 13: Contact page

\section{FUTURE SCOPE}

Blockchain structure can also be used in hospitals for savings the overall details of the hospital.

\section{CONCLUSION}

Data security is one of the major features of block chain technology. We are develop digital certificate using block chain. this system reduces the likelihood of certificate forgery. Its also reduced the chances of missing documents. The process of are generate e-certificate and QR code. Its very useful for paper less work. Companies or organizations can thus inquire for information on any certificate from the system. In final result, the system assures information accuracy and security.

\section{ACKNOWLEDGEMENT}

In our endeavour to achieve the success in completing our project. we take this opportunity to express our deep feelings of preciation to our guide prof. Santosh.A.Darade for his valuable guidance and kind cooperation throughout the period of week he has undertaking which has been instrumental in success of seminar. Finally special thanks to our friends, family member and all other who have helped us directly or indirectly fors successful completion of this work.

\section{REFERENCES}

[1]TengyuYu ,Blockchain operation principle analysis :5 key,iThome,https://www.ithome.com.tw/news/105374

[2]BenyuanHe,"An Empirical Study of Online Shopping Using Blockchain Technology", Department Of Distribution Management ,Takming University of Science and Technology,Taiwan,R.O.C ,2017

[3] XiupingLin,"Semi-Centralized Block-chain Smart Contracts:Centralized Verification And Smart Computing Under Chains In Etherum Block chain”,Department of Information Engineering,National Taiwan University, Taiwan,R.O.C, 2017. 
[4]Yong Shi,"Secure Storage Service Of Electronics Ballot system based on blockchain algorithm", Department Of Computer Science,TsingHua University, Taiwan . R.O.C ,2017.

[5]Zhenzhi Qiu,'Digital Certificate for a painting based on block chain technology",Department of Information and Finance Management,National Taipei University of Technology,Taiwan,R.O.C,2017.

[6]JingyuanGao,The rise of virtual currencies!Bitcoin takes the lead,and the other 4 kinds can't be missed .Digital Age,https://www.bnext.com.tw/article/47456/ bitcoin-ether-litecoin-ripple-differences-betweencryptocurrencies.

[7] Cristobal Romero, Sebastian Ventura "Educational Data Mining: A Review of the State of the Art", VOL. 40, 2010

[8] SHI WANG Pei-ji1, SHI Lin1 ,BAI Jin-niu2, ZHAO Yu-lin "Mining Association Rules Based on Apriori Algorithm and Application",2009.

[9]Manoj BehrouzMinaei-Bidgoli, Deborah A. Kashy, GerdKortemeyer, William F. Punch"Predicting student performance:An application of Data Mining methods with an educational web-based system",2003.

[10] B.Morton,Short-lived certificates, Secure Browsing,SSL,Technical,2012. 